\title{
Cytotoxicity analysis of etoposide and cisplatin on cell lines from human lung cancer and normal human lung
}

\author{
Davou $\mathrm{GI}^{1 *}$, Chuwang $\mathrm{NJ}^{2}$, Essien UC', Choji TPP ${ }^{3}$, Echeonwu $\mathrm{BC}^{4}$ and Lugos MD1 \\ ${ }^{1}$ Department of Medical Laboratory Science, Faculty of Health Sciences and Technology, College of Health Sciences, \\ University of Jos, Jos, Plateau State, Nigeria. \\ ${ }^{2}$ Department of Anatomy, Faculty of Basic Medical Sciences, College of Health Sciences, University of Jos, Jos, Plateau \\ State, Nigeria. \\ ${ }^{3}$ Central Diagnostic Division, National Veterinary Research Institute, Vom, Plateau State, Nigeria. \\ ${ }^{4}$ Department of Histopathology and Cytology, Federal College of Veterinary and Medical Laboratory Technology, Vom, \\ Plateau State, Nigeria.
}

Accepted 17 April, 2019

\begin{abstract}
Lung cancer is the leading cause of cancer-related deaths in the world with non-small cell lung cancer (NSCLC) making up a large majority of all cases. Despite advancement and discoveries in cancer therapy, treatment of this disease has been less successful due to serious side effects and drug resistance. Therefore, there is a need to research into new therapeutic approaches for this disease. This study, therefore, evaluated the effect of two common cytotoxic lung cancer drugs, the etoposide and cisplatin on two lung cell lines, A549 (lung cancer cell line) and BEAS-2B (normal lung virus-transformed cell line). Our study was aimed at testing the response of normal lung and lung cancer cells to different concentrations of etoposide and cisplatin over a period of time in order to determine the cytotoxic effect of these drugs. The cells were grown in culture plates and MTT assays were performed on both cell lines in order to determine each cell line's IC50 in response to various concentrations of cisplatin and etoposide over a maximum period of $72 \mathrm{hrs}$. Our results showed a cytotoxic effect on both cell lines. Unexpectedly, higher drug toxicity was observed on BEAS-2B compared to A549 cell lines. Consequently, this data highlights the necessity for further search of a more selective and effective drug that has minimal toxicity on the normal cells for effective treatment of NSCLC and lung cancer in general.
\end{abstract}

Keywords: Cytotoxicity, cell culture, lung cancer, cell lines, etoposide, cisplatin.

*Corresponding author. E-mail: gwomforreal2015@gmail.com.

\section{INTRODUCTION}

Lung cancer is one of the most commonly occurring and deadliest human cancers worldwide (Pervaiz et al., 2010); with an annual incidence of 1.8 million (Yousheng et al. 2016). The mortality rate of lung cancer is up to 1.59 million globally, giving rise to the highest cancer mortality figure (Cheng et al., 2016). Lung cancers are largely classified into primary lung carcinoma (PLC) and secondary lung carcinoma (SLC) based on the organ of origin. Usually, the most common form of lung cancer is the primary lung cancer which originates from the lungs. Morphologically, two types of PLC, the small-cell lung carcinoma (SCLC) and the non-small-cell lung carcinoma (NSCLC) are known. The NSCLC is reported to be the most commonly occurring cancer globally (Jemal et al., 2013).

Lung cancer is not curable. However, it is usually treated using drugs in a combinational chemotherapy approach. The most common first-line combination 
therapy for the treatment of lung carcinoma is the combination of $\mathrm{E}$ - etoposide (also known as vepesid, eposin or etopophos) and $\mathrm{P}$ - cisplatin (also known as platinum), commonly referred to as EP or PE in different dose combinations to achieve effective therapy. This therapeutic approach has suffered setbacks due to drug toxicity, side effect and resistance. The major cause of drug-toxicity is due to drug interaction with DNA, which could result to the following adverse effects, nephrotoxicity, hepatotoxicity and cardiotoxicity. Mechanism of drug resistance by cancer cells are developed through some modifications such as; changes in drug transport, accelerated drug detoxification, increase in DNA repair, better tolerance mechanism in DNA damage, and modifications in apoptotic pathways (Dasari and Tchounwou, 2014; Huang et al., 2017). Thus the need to further evaluate the toxicity of drugs on lung cancer cells.

In this study, we tested the toxicity effect of etoposide and cisplatin on two cell lines A549 and BEAS-2B in vitro in order to evaluate how lung cancer cells and normal lung cells respond to chemotherapy with these cytotoxic drugs.

\section{MATERIALS AND METHODS}

\section{The cell lines}

The A549 cell line used for this study originates from a 58-year Caucasian male who had lung carcinoma. These cells are of human alveoli basal squamous epithelial origin that adheres as a monolayer on the bottom surface of culture flask. Meanwhile, the BEAS-2B cell lines are derived from non-cancerous normal human bronchial epithelium. After isolation, they were transformed by viral infection with an adenovirus hybrid 12-SV40 that made them capable of forming colonies in semisolid medium without necessarily being tumorigenic. Both cell lines were kindly provided by Professor Marija Krstic-Demonacos laboratory at Cockcroft Building, University of Salford, Manchester UK, with both passages Number $(P \quad 17)$ in $-80^{\circ} \mathrm{C}$. Both cells were resuscitated in 15 millimetres $(\mathrm{ml})$ of $90 \%(\mathrm{v} / \mathrm{v})$ RPMl-1640 (Sigma-Aldrich) with $1 \mathrm{ml}$ of $2 \mathrm{mM}$ L-glutamine (Sigma-Aldrich), supplemented with $10 \mathrm{ml}$ of $10 \%(\mathrm{v} / \mathrm{v})$ foetal bovine serum (FBS) and a mix-solution of $50 \mathrm{IU} / \mathrm{ml}$ penicillin and $50 \mu \mathrm{g} / \mathrm{ml}$ streptomycin antibiotics in a T25 flask (Nunc).

\section{Cell culture and maintenance of adherent cell lines}

The cell lines were incubated at $37^{\circ} \mathrm{C}$ in a humidified atmosphere of $5 \% \mathrm{CO}_{2}$ (SANYO electric - MCO-17A1C). The medium was replaced after 24 hours of incubation. The doubling time for the A549 cell line is 22 hours, whereas BEAS-2B has a doubling time of approximately 26 hours. The cells reached a confluence of approximately $70-80 \%$ every 3 days and were then subcultured using sterile phosphate buffered saline $(1 \times \mathrm{PBS})$ to wash off contaminants from the culture and $0.25 \%(\mathrm{w} / \mathrm{v})$ of trypsin-EDTA (Sigma-Aldrich) for cell detachment, in order to enable re-seeding for continues cultivation of cell line in new culture flasks containing fresh media.

After 3-4 successful splitting and subculture of the cells, a working bank of cells ( 6 vials each at $5.9 \times 10^{6} / \mathrm{ml}$ and $\left.6.1 \times 10^{5} / \mathrm{ml}\right)$ were frozen at $-80^{\circ} \mathrm{C}$ in $1.8 \mathrm{ml}$ of $90 \% \mathrm{FBS}$ and $200 \mu \mathrm{l}$ of $10 \%$ dimethyl sulfoxide (DMSO).

\section{Seeding of plates}

Cells were detached from the culture flask after subculture, and a viable cell count was performed using a INCYTO C-chip ${ }^{\text {TM }}$ disposable plastic haemocytometer (SKC FILMS INC, North America), to ascertain the number of cells to be seeded per well. We prepared a concentration of two thousand cells per hundred microlitres of fresh culture media for both cell lines and transferred $100 \mu \mathrm{l}$ into each assay well in a 96 -flat-bottomed microtitre plate. The cells were seeded in triplicate for each drug concentration with the first set having zero drug concentration (to serve as control) in each plate for $24 \mathrm{~h}$ at $37^{\circ} \mathrm{C}$ with $5 \% \mathrm{CO}_{2}$ environment, in order to enable attachment of adherent cells to the bottom surface of the wells for optimum growth before exposure to cytotoxic drugs. Three sets of plates were seeded for the cytotoxic reaction at $24 \mathrm{~h}, 48 \mathrm{~h}$ and 72-h incubation for both etoposide and cisplatin and both cell lines.

\section{Incubation with etoposide and cisplatin}

After 24-h incubation, cells were treated with etoposide and cisplatin at different concentrations with the highest concentration of 20 and $200 \mu \mathrm{M}$, respectively. Both solutions were prepared from a $10 \mathrm{mM}$ stock solution and serially diluted to produce the following concentrations; $10,5,2.5,1.25,0.625,0.3125 \mu \mathrm{M}$ for etoposide and $100,50,25,12.5,6.25,3.125 \mu \mathrm{M}$ for cisplatin. This was performed for both the two cell lines to enable incubation at 24, 48 and $72 \mathrm{~h}$ under $37^{\circ} \mathrm{C}$ with $\mathrm{CO}_{2}$ environment. This will allow the interaction of the drugs with the viable cells, already in a favourable growth condition.

\section{MTT (3-4, 5-dimethylthiazol-2, 5 diphenyl tetrazolium bromide) assay}

The MTT colourimetric assay was used to assess the viability and proliferation of cells. The mechanism of this test is based on the reduction of an aqueous solution monotetrazolium salt (MTT) to purple insoluble formazan dye by the NADH-dependant oxidoreductases of metabolically active cells (Berridge et al., 2005).

The MTT reagent (Sigma-Aldrich) was made up at $3 \mathrm{mg} / \mathrm{ml}$ in PBS. Following the incubation of cells with a cytotoxic agent (drugs), $50 \mu \mathrm{l}$ MTT solution was added to each of the seeded wells. Plates were then incubated $\left(37^{\circ} \mathrm{C}, 5 \% \mathrm{CO}_{2}\right)$ for four hours, after which solution was then aspirated from wells being careful to avoid dislodging the purple coloured formazan crystals formed in the bottom. Next, $100 \mu \mathrm{l}$ of DMSO was added to each well to dissolve the crystals. MultiSkan Ascent Plate Reader (Thermo Fisher Scientific, US) was used to measure the absorbance of each microtitre well at 540 and $690 \mathrm{~nm}$. The absorbance at the $690 \mathrm{~nm}$ (background/correction wavelength) is subtracted from the absorbance reading at 540 to enable the percentage viability of cells in each well to be determined, relative to untreated controls. The difference between these two readings was used for the analysis. The mean of the triplicate reading for two separate runs of the same cells and drug was used for statistical analysis and calculation of the IC-50 (inhibition concentration) values of both etoposide and cisplatin.

IC50 is applied to measure drug potency antagonist. This corresponds to the concentration of drug required for $50 \%$ inhibition in vitro. A drug IC50 can be determined by designing a dose response curve and analyzing the antagonistic effect of different drug concentration on reversing agonist activity. This can be calculated by determining the concentration of an antagonist needed to inhibit $50 \%$ of maximum biological response of agonist (Beck et al., 2017). 
Statistical analysis of cells treated with cytotoxic drugs

In order to investigate the statistical significance of our data, a paired sample t-test analysis was adopted, and analysis was carried out (using the Minitab statistical software) to arrive at the $p$ values.

\section{RESULTS}

Analysis of cytotoxicity of chemotherapeutic drugs in human lung cancer and normal cell lines using the MTT Assay

In order to determine the cytotoxicity of etoposide and cisplatin chemotherapeutic drugs on both normal and cancer cells, both normal virus-transformed lung epithelial cells BEAS-2B and lung cancer A549 cell lines were exposed to treatment in vitro with the cytotoxic drugs. Both drugs act via DNA damage mechanism leading to the activation of p53, which on activation initiate DNA damage response activity that is evident by quiescence cells or dead cells on the cell culture. These experiments were performed with different drug concentrations at 2000 cell concentration per well for 24h, 48-h and 72-h. We hypothesized a significant cell death with increasing incubation times and concentrations of drugs with variation in effects on cancerous versus noncancerous cells. Details of significant $p$-values and $t$-values are provided in Table 1. The BEAS-2B normal lung virus-transform cell line was also intended to serve as a positive control since we expect no resistance from this normal cell lines to the cytotoxic effect of etoposide and cisplatin. Furthermore, the first row on each plate had only seeded cells without any drug, in order to serve as a negative control for the experiment. Consequently, these experiments reveal a consistent drop in percentage relative viability with increasing drug concentration and incubation.

\section{Analysis of cells treated with cytotoxic drugs after 24-hour incubation}

The 24-hour incubation indicated a consistent reduction in cells viability with increased drug concentration as expressed in Figure 1. Furthermore, the cytotoxic drugs (etoposide and cisplatin) were able to cause greater cell death on BEAS-2B cells than on A549 cells, after exposing both cell lines to the same concentrations and treatment conditions.

Table 1. Table of P-values.

\begin{tabular}{lccc}
\hline Cell type/Treatment & Drug Conc. $(\mu \mathrm{M})$ & T-values & Significant $\mathbf{P}$ \\
\hline BEAS-2B with etoposide at 24 hours & 1.25 & 21.000 & 0.0303 \\
BEAS-2B with cisplatin at 24 hours & 50 & 26.500 & 0.0240 \\
A549 with etoposide at 48 hours & 1.25 & 14.333 & 0.0443 \\
A549 with cisplatin at 48 hours & 25 & 23.000 & 0.0277 \\
BEAS-2B with etoposide at 48 hours & 2.5 & 23.667 & 0.0269 \\
BEAS-2B with cisplatin at 48 hours & 6.25 & 14.000 & 0.0454 \\
A549 with etoposide at 72 hours & 0.3125 & 27.000 & 0.0236 \\
A549 with cisplatin at 72 hours & 3.125 & 18.500 & 0.0344 \\
BEAS-2B with etoposide at 72 hours & 0.3125 & 28.500 & 0.0223 \\
BEAS-2B with cisplatin at 72 hours & 3.125 & 28.333 & 0.0225 \\
\hline
\end{tabular}

\section{Analysis of cells treated with cytotoxic drugs after 48-hour incubation}

The 48-hour incubation as expressed in Figure 2 also indicated a consistent reduction in cells viability with increasing drug concentration. We also notice less viability on BEAS-2B treated with cytotoxic drugs (etoposide and cisplatin) than in A549 cells treated with the same drugs concentration and conditions.

\section{Analysis of cells treated with cytotoxic drugs after 72-hour incubation}

The 72-hour incubation as expressed in Figure 3 also indicated a consistent reduction in cells viability with increasing drug concentration. Also, the cytotoxic drugs (etoposide and cisplatin) were able to cause greater cell death as evidenced in virtually all drug concentrations on both A549 cells and BEAS-2B cells.

\section{Statistical analysis of cells treated with cytotoxic drugs}

After 24-hours drug incubation, the cytotoxic drugs were only able to cause significant death on BEAS-2B at 1.25 and $50 \mu \mathrm{M}$ drug concentration for etoposide and cisplatin respectively. Whereas the death caused on A549 cells took 48-hour to achieved significant values of 1.25 and 


\section{A A549 cells treated with etoposide at $24 \mathrm{hrs}$}

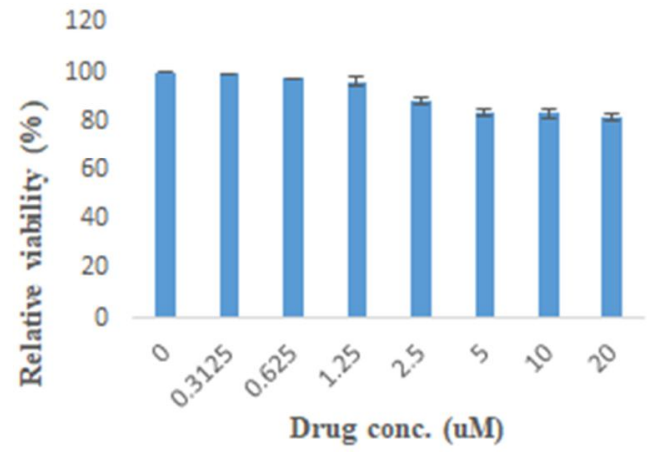
B 549 cells treated with
cisplatin at $24 \mathrm{hrs}$

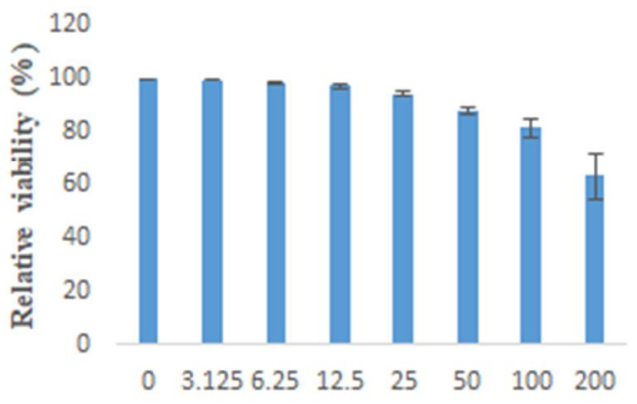

Drug conc. (uM)

\section{BEAS-2B cells treated} with etoposide at $24 \mathrm{hrs}$

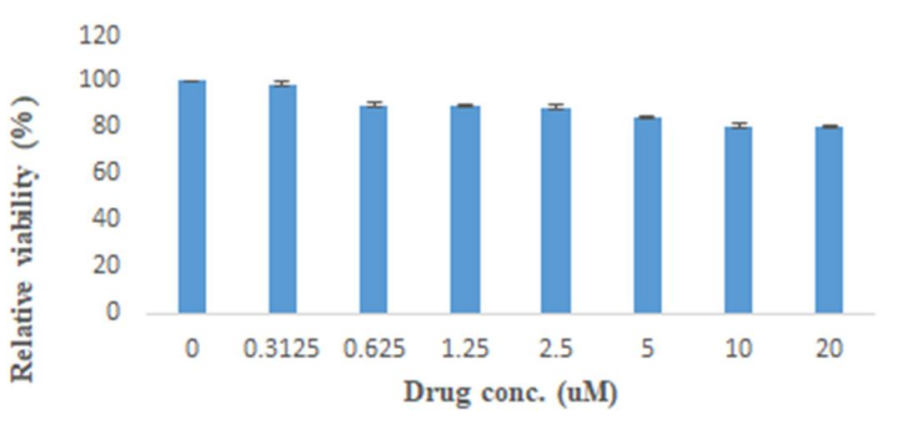

\section{BEAS-2B cells treated} with cisplatin at $24 \mathrm{hrs}$

Figure 1. 24-hour incubation of A549 and BEAS-2B cells treated with etoposide and cisplatin. The results of MTT assay following 24 hours incubation of 2000 A549 and BEAS-2B cells per well each with varied concentrations of etoposide and cisplatin are represented in figures $A \& B$ and $C \& D$ respectively. The vertical axis indicates the percentage relative viability (i.e. live cells) whereas the horizontal axis indicates the drug varied concentration.

$12.5 \mu \mathrm{M}$ drug concentration for etoposide and cisplatin, respectively. Also, both cytotoxic drugs achieved significant cell death on both cell lines after 72-hours. Furthermore, a significant death was achieved in virtually all drug concentrations for both cytotoxic drugs on both cell lines after 72-hour incubation.

\section{Analysis of IC50 values of 2000 cells treated with cytotoxic drugs}

In order to investigate the IC50 (inhibition concentration) values of the cytotoxic drugs on A549 cells and BEAS-2B cells at 24-hour, 48-hour and 72-hour incubation of 2000 cells per well. Values from each experiment along with their corresponding drug concentrations were inserted into the IC50 calculator software, experiments with applicable IC50 values were identified as indicated in Table 2. We were only able to achieve IC50 values of $47.43 \mu \mathrm{M}$ after 24-hour incubation for BEAS-2B cells treated with cisplatin. After 48-hour incubation, IC50 values of 4.36 and $8.63 \mu \mathrm{M}$ for etoposide and cisplatin respectively were achieved on BEAS-2B cells, whereas only $36.94 \mu \mathrm{M}$ of cisplatin was achieved on A549 cells. The 72-hour experiment was able to achieve IC50 values for both drugs treated on both cell lines, with IC50 values of 3.49 and $6.59 \mu \mathrm{M}$ for etoposide and cisplatin on A549 cells respectively, whereas IC50 values of 2.10 and 4.15 $\mu \mathrm{M}$ for etoposide and cisplatin on BEAS-2B cells respectively were obtained. 


\section{A $\quad$ A549 cells treated with etoposide at $48 \mathrm{hrs}$ \\ B A549 cells treated with cisplatin at $48 \mathrm{hrs}$}
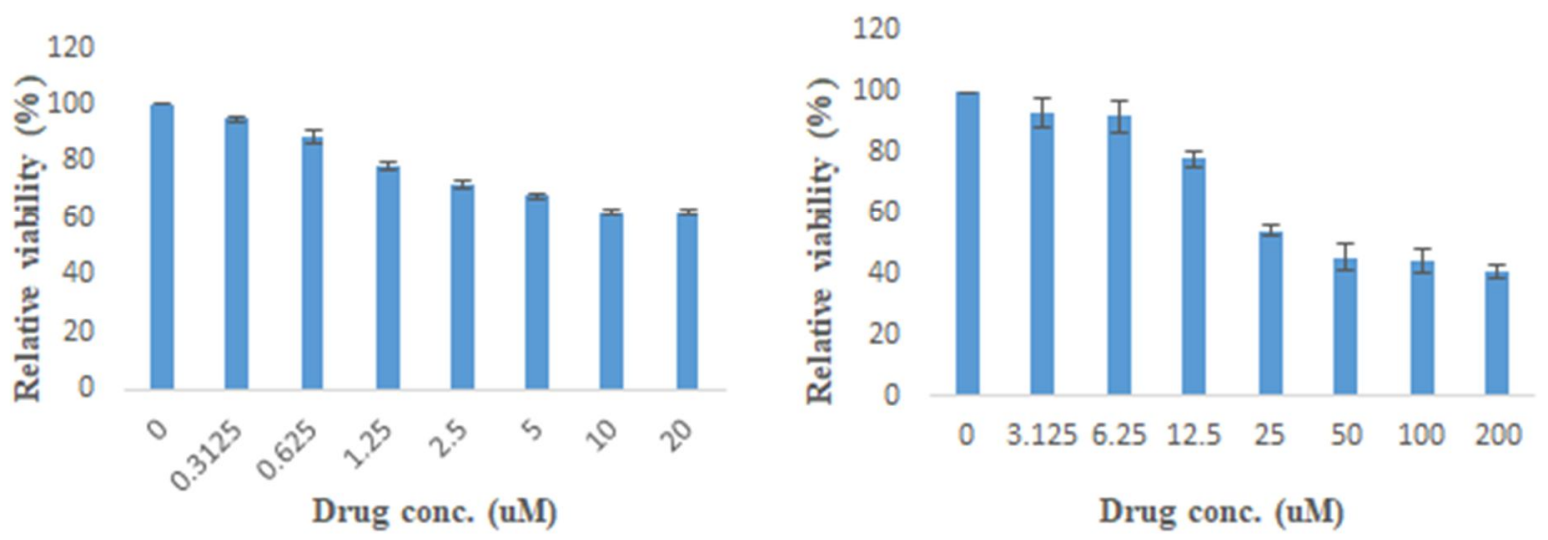
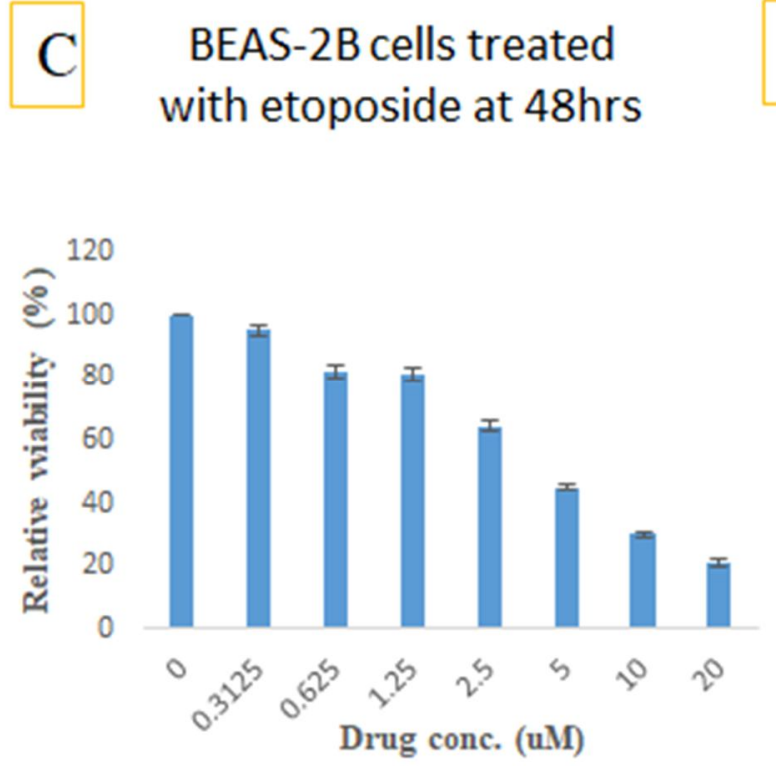

\section{BEAS-2B cells treated with cisplatin at $48 \mathrm{hrs}$}

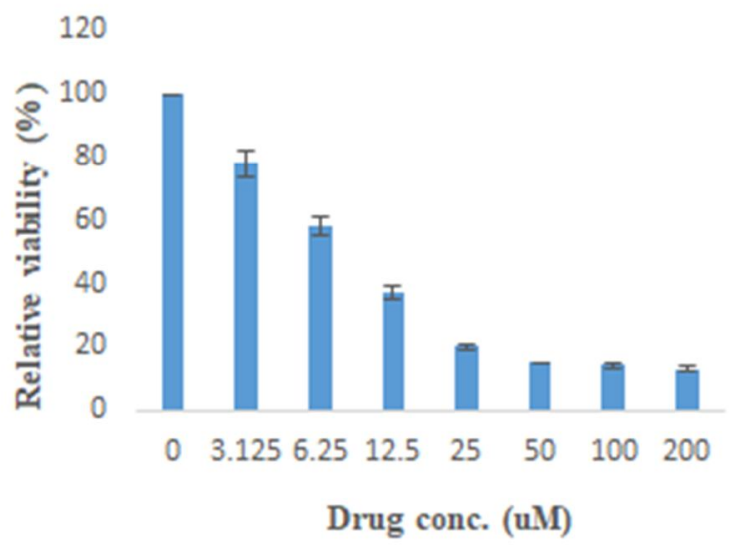

Figure 2. 48-hour incubation of $A 549$ and BEAS-2B cells treated with etoposide and cisplatin. The results of MTT assay following 48 hours incubation of 2000 A549 and BEAS-2B cells per well each with varied concentrations of etoposide and cisplatin are represented in figures A \& B and C \& D respectively. The vertical axis indicates the percentage relative viability (i.e. live cells) whereas the horizontal axis indicates the drug varied concentration.

\section{DISCUSSION}

This study was primarily designed to investigate the cytotoxicity of etoposide and cisplatin (the common lung cancer drugs) on lung cancer cells and normal lung cells. Sadly, the treatment of this disease has been less successful despite advancement in discoveries for cancer therapy as the disease is identified to have the highest annual cancer mortality rate of over 1.6 million globally (McGuire, 2016). The current therapeutic approaches have been shown to present with drug toxicity, side effect and resistance (Dasari and Tchounwou, 2014; Huang et al., 2017), hence the outcome of this study will enhance our understanding of the mode of action of the conventional lung cancer drugs and advance for the search of better future treatment approach for lung cancer.

Our data clearly showed that both drugs exhibit significant cytotoxic effects on both the lung cancer cells, A549 and normal lung virus-transformed cells, BEAS-2B, with significantly higher cytotoxicity on BEAS-2B cells. This was confirmed by significantly lower percentage viability on the BEAS-2B normal cells within 24-hour incubation, as it took about $48 \mathrm{~h}$ to achieve similar low 


\begin{tabular}{c|c} 
A549 cells treated with \\
etoposide at $72 \mathrm{hrs}$
\end{tabular} B $\begin{gathered}\text { A549 cells treated with } \\
\text { cisplatin at } 72 \mathrm{hrs}\end{gathered}$
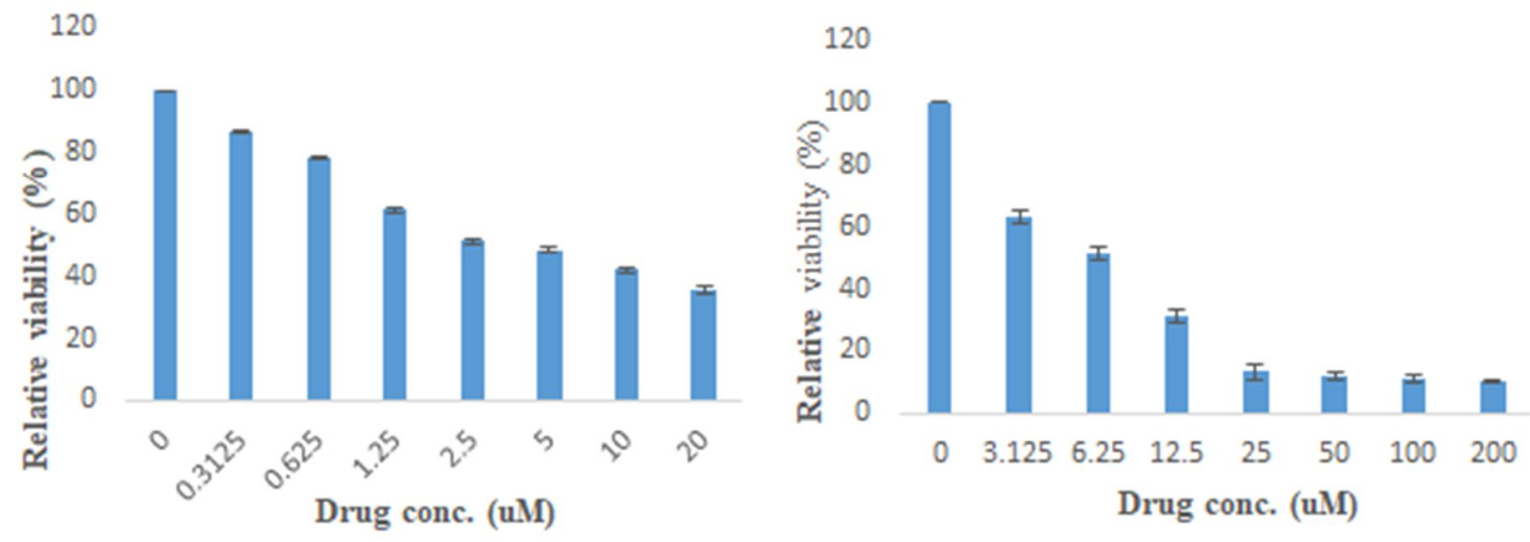

\section{BEAS-2B cells treated
with etoposide at $72 \mathrm{hrs}$}

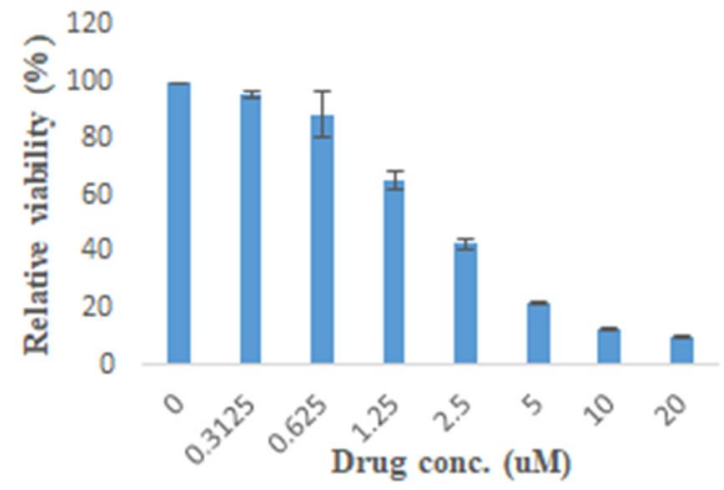
DEAS-2B cells treated with
cisplatin at $72 \mathrm{hrs}$

Figure 3. 72-hour incubation of A549 and BEAS-2B cells treated with etoposide and cisplatin. The results of MTT assay following 72 hours incubation of 2000 A549 and BEAS-2B cells per well each with varied concentrations of etoposide and cisplatin are represented in figures $A \& B$ and $C \& D$ respectively. The vertical axis indicates the percentage relative viability (i.e. live cells) whereas the horizontal axis indicates the drug varied concentration.

levels of percentage viability with the same concentration of drugs in the A549 cancer cells. This signifies that both drugs have the potential to destroy both normal and cancerous cells. Unexpectedly, both drugs have shown a higher cytotoxic effect on normal cells in vitro compared to the lung cancer cells. Furthermore, the investigations also gave a consistently lower IC50 (inhibition concentration) values for the BEAS-2B cells than A549 cells, and it took up to $72 \mathrm{~h}$ to achieve IC50 value with etoposide treatment on A549 cells. The rise in the IC50 levels of normal cells, BEAS-2B in comparison with the cancerous cells, A549 indicates a greater drug resistance by the cancerous cells compared to normal lung cells.

This study presents great insight into the drug toxicity and side effect witnessed in conventional lung cancer therapy, as shown by higher cytotoxicity of both drugs on normal lung cells. The lower cytotoxicity of both drugs on lung cancer cells indicates some level of resistance of the cancer cells to etoposide and cisplatin. Consequently, these could be the reason for lung cancer showing one of the highest mortality rates among all cancers. However, this insight is based on data obtained from in vitro 
Table 2. Table of IC 50s.

\begin{tabular}{clc}
\hline Plant no. & Cell type/Treatment & IC $50(\mu \mathrm{M})$ \\
\hline 1 & A549 cells at 24 hours with etoposide & NA \\
2 & A549 cells at 24 hours with cisplatin & NA \\
3 & BEAS-2B cells at 24 hours with etoposide & NA \\
4 & BEAS-2B cells at 24 hours with cisplatin & 47.43 \\
5 & A549 cells at 48 hours with etoposide & NA \\
6 & A549 cells at 48 hours with cisplatin & 36.94 \\
7 & BEAS-2B cells at 48 hours with etoposide & 4.36 \\
8 & BEAS-2B cells at 48 hours with cisplatin & 8.63 \\
9 & A549 cells at 72 hours with etoposide & 3.49 \\
10 & A549 cells at 72 hours with cisplatin & 6.56 \\
11 & BEAS-2B cells at 72 hours with etoposide & 2.10 \\
12 & BEAS-2B cells at 72 hours with cisplatin & 4.15 \\
\hline
\end{tabular}

Key: NA - not applicable.

analysis. A further study using an in vivo approach or clinical trial may provide further confirmation of data.

Several studies have shown that tumour cells are capable of developing certain adaptive and resistance conditions such as hypoxic conditions which interfere with the mechanisms of action for most cancer chemotherapeutic drugs (Teicher, 1994; Cosse and Michiels, 2008; Adamski et al., 2013), leaving the normal cells more vulnerable to the cytotoxic effects of these drugs. A study carried out by Lee et al. (2006) reveals the role of hypoxic conditions indirectly reducing the efficacy of etoposide-mediated apoptosis on lung cancer cells (Song et al., 2006). This reduced efficacy is as a result of the activation of phosphatidylinositol 3-kinase (PI3K)/AKT and extracellular signal-regulated kinase (ERK) pathways (Lee et al., 2006). These pathways are very critical in cell cycle regulation and are usually dysregulated in most cancers, thus they function by influencing cellular quiescence, normal cell proliferation, tumour proliferation and cellular longevity (Graupera et al., 2008, Jia et al., 2008, Liu et al., 2009; Poulikakos and Solit, 2011). This, has also indicated an indirectly reduced efficacy of cisplatin treatment on non-small cell lung cancer (NSCLC) cells in a hypoxic-induced environment. According to the Lee study, this hypoxic-induced chemoresistance is mediated through the hypoxic inducible

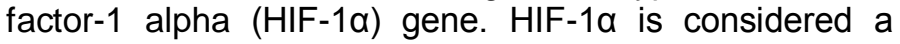
major marker for the transcriptional regulator of cellular growth response anchor via hypoxia inducement. The overexpression of this gene is highly associated with most cancers (lyer et al., 1998; Semenza, 2003). Another study on the loss of cytoplasmic CDK1 on human lung cancer cells was shown to be responsible for poorer survival in NSCLC as a result of chemotherapeutic resistance. The study highlights that the loss of CDK1 and CDK1-associated genes in multiple cell lines is largely responsible for the chemotherapeutic resistance and poor survival in lung cancer cell lines (Zhang et al.,
2011). Furthermore, a study conducted by Sen et al., revels up to $20 \%$ nonresponse to chemotherapy with etoposide and cisplatin. This rate excludes the partial response group that forms part of the remaining $80 \%$ of the patients in a comparative study between etoposide/cisplatin and docetaxel/cisplatin chemotherapy treatment in patients with advanced NSCLC (Sen et al., 2016).

In conclusion, this research reveals that A549 lung cancer cells have greater resistance to the cytotoxic drugs when compared with the effect of the drugs on the normal lung virus-transformed BEAS-2B cells, as demonstrated by the high efficacy of drugs on normal cells over cancerous cells given same treatment conditions. Potentially, this could be a cause of the chemotherapeutic failure being witnessed in lung cancer therapy and its associated side effects. However, the results revealed by these experiments is still far from achieving the ultimate goal of the search for better therapy for lung cancer, as experiments for the expression of genes responsible in DNA damage response such as p53 was not carried out. Further research to investigate the role of p53 and its upstream and downstream genes in tissue sections will be required to provide more insights into understanding the interactions and the nature of genes involved in DNA damage response.

\section{ACKNOWLEDGEMENTS}

I want to use this opportunity to thank my MSc supervisor Professor Marija Krstic-Demonacos (MKD), whose tutorship and mentoring skills guided me throughout my research and supported this research with reagents. Also not forgetting the PhD students in MKD's lab; Emyr Bakker and Firozah Ashtiani for their support in carrying out experiments. My greatest gratitude goes to the 
tertiary education trust fund (TETFUND) for providing the funds, and the University of Jos for finding me worthy of being a benefactor for the scholarship to do my MSc in the University of Salford, Manchester UK. There was no conflict of interest.

\section{REFERENCES}

Adamski J, Price A, Dive C, Makin G, 2013. Hypoxia-induced cytotoxic drug resistance in osteosarcoma is independent of HIF-1 alpha. PloS one, 8(6): e65304.

Beck B, Chen YF, Dere W, Devanarayan V, Eastwood BJ, Farmen MW, Iturria SJ, Iversen PW, Kahl SD, Moore RA, 2017. Assay operations for SAR support. Assay Guidance Manual [Internet], Eli Lilly \& Company and the National Center for Advancing Translational Sciences.

Berridge MV, Herst PM, Tan AS, 2005. Tetrazolium dyes as tools in cell biology: new insights into their cellular reduction. Biotechnol Ann Rev, 11: 127-152.

Cheng TYD, Cramb SM, Baade PD, Youlden DR, Nwogu C, Reid ME, 2016. The international epidemiology of lung cancer: latest trends, disparities, and tumor characteristics. J Thoracic Oncol, 11(10): 1653-1671.

Cosse JP, Michiels C, 2008. Tumour hypoxia affects the responsiveness of cancer cells to chemotherapy and promotes cancer progression. Anti-Cancer Agents Med Chem, 8(7): 790-797.

Dasari S, Tchounwou PB, 2014. Cisplatin in cancer therapy: molecular mechanisms of action. European J Pharmacol, 740: 364-378.

Graupera M, Guillermet-Guibert J, Foukas LC, Phng LK, Cain RJ, Salpekar A, Pearce W, Meek S, Millan J, Cutillas PR, 2008. Angiogenesis selectively requires the $\mathrm{p} 110 \alpha$ isoform of PI3K to control endothelial cell migration. Nature, 453(7195): 662

Huang CY, Ju DT, Chang CF, Reddy PM, Velmurugan BK, 2017. A review on the effects of current chemotherapy drugs and natural agents in treating non-small cell lung cancer. Biomedicine 7(4): 23.

Huang F, Pan B, Wu J, Chen E, Chen L, 2017. Relationship between exposure to PM2. 5 and lung cancer incidence and mortality: a metaanalysis. Oncotarget, 8(26): 43322.

lyer NV, Kotch LE, Agani F, Leung SW, Laughner E, Wenger RH, Gassmann M, Gearhart JD, Lawler AM, Aimee YY, 1998. Cellular and developmental control of $\mathrm{O} 2$ homeostasis by hypoxia-inducible factor 1a. Genes Dev, 12(2): 149-162.

Jemal A, Simard EP, Dorell C, Noone AM, Markowitz LE, Kohler B, Eheman C, Saraiya M, Bandi P, Saslow D, Cronin KA, Watson M, Schiffman M, Henley SJ, Schymura MJ, Anderson RN, Yankey D, Edwards BK, 2013. Annual report to the nation on the status of cancer, 1975-2009, featuring the burden and trends in human papillomavirus (HPV)-associated cancers and HPV vaccination coverage levels. J Natl Cancer Inst, 105(3): 175-201.

Jia S, Liu Z, Zhang S, Liu P, Zhang L, Lee SH, Zhang J, Signoretti S, Loda M, Roberts TM, 2008. Essential roles of PI (3) K-p110 in cell growth, metabolism and tumorigenesis. Nature, 454(7205): 776.

Lee SM, Lee CT, Kim YW, Han SK, Shim YS, Yoo CG, 2006. Hypoxia confers protection against apoptosis via PI3K/Akt and ERK pathways in lung cancer cells. Cancer Lett, 242(2): 231-238.

Liu P, Cheng $\mathrm{H}$, Roberts TM, Zhao JJ, 2009. Targeting the phosphoinositide 3-kinase pathway in cancer. Nature Reviews Drug Discovery, 8(8): 627-644.

McGuire S, 2016. World cancer report 2014. Geneva, Switzerland: World Health Organization, international agency for research on cancer, WHO Press, 2015, Oxford University Press.
Parvaiz AK, Satish KK, Mohammad MS, Reyaz AT, Azra S, 2010. Lung cancer in the Kashmir valley. Lung India, 27:131-7.

Poulikakos PI, Solit DB, 2011. Resistance to MEK inhibitors: should we co-target upstream? Sci Signal, 4(166): pe16.

Semenza GL, 2003. Targeting HIF-1 for cancer therapy. Nat Rev Cancer, 3(10): 721.

Sen F, Tambas M, Ozkaya K, Guveli ME, Ciftci R, Ozkan B, Oral EN, Saglam EK, Saip P, Toker A, Demir A, Firat P, Aydiner A, Eralp Y, 2016. Concomitant etoposide and cisplatin provided improved survival compared with docetaxel and cisplatin in patients with locally advanced non-small cell lung cancer treated with chemoradiotherapy. Medicine, 95(30):e4280

Song X, Liu X, Chi W, Liu Y, Wei L, Wang X, Yu J, 2006. Hypoxiainduced resistance to cisplatin and doxorubicin in non-small cell lung cancer is inhibited by silencing of HIF-1a gene. Cancer Chemother Pharmacol, 58(6): 776-784.

Teicher BA, 1994. Hypoxia and drug resistance. Cancer Metastasis Rev, 13(2): 139-168.

Yousheng M, Ding Y, Jie $\mathrm{H}$ and Mark JK, 2016. Epidemiology of Lung Cancer. Surg Oncol Clin N Am, 25: 439-45.

Zhang C, Elkahloun AG, Robertson M, Gills JJ, Tsurutani J, Shih JH, Fukuoka J, Hollander MC, Harris CC, Travis WD, Jen J, Dennis PA 2011. Loss of cytoplasmic CDK1 predicts poor survival in human lung cancer and confers chemotherapeutic resistance. PLoS One, 6(8): e23849.

Citation: Davou Gl, Chuwang NJ, Essien UC, Choji TPP, Echeonwu BC Lugos MD, 2019. Cytotoxicity analysis of etoposide and cisplatin on cell lines from human lung cancer and normal human lung. Int Res J Med Med Sci, 7(2): 40-47. 